\title{
DESIGNING MEASURING EQUIPMENT AND Camera Systems in MANUfaCturing
}

\author{
Micieta, B.; JANCusova, M.; MACEK, P. \& DURICA, J.
}

Abstract: The article deals with a design of measuring equipment used camera systems designed for optical measurements of components large dimensions in manufacturing. We designed two types of positioning subsystems to the measuring equipment and three variants of the measuring subsystems in specification of measured parts. It is a new approach designing for the automatic measurements of components in the wood industry and other industry sectors. Other area of article is focused to basic steps in designing of assembly system. On both positioning mechanisms with interface for connecting of all three measuring technologies is designed complete assembly. Prototype of the automated measuring equipment which is proposed based of unattended technologies with possibility of applying also other of different sectors industries.

Key words: optical measurements, controlling, automation, modularity, assembly
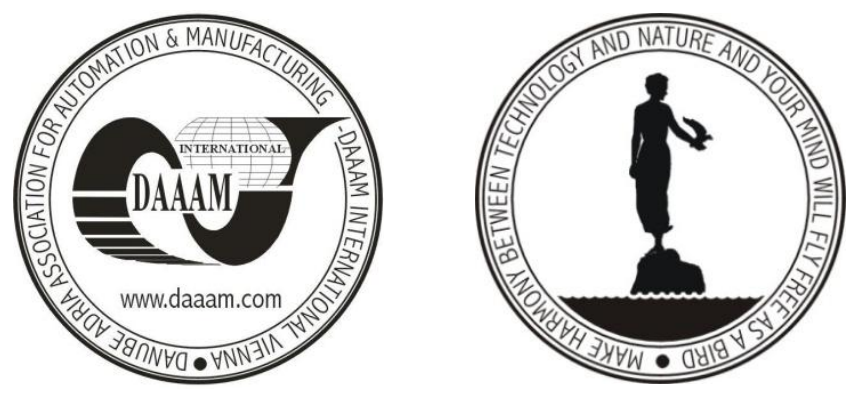

Authors' data: Prof. Ing. PhD. Micieta, B[ranislav]; Ing. PhD. Jancusova, M[aria]; Ing. PhD. Macek, P[eter]; Ing. PhD. Durica, J[an], University of Zilina, Univerzitna 1,01026,Zilina,Slovakia,branislav.micieta@fstroj.uniza.sk,maria.jancusova @ fstroj.un iza.sk, peter.macek@fstroj.uniza.sk, jan.durica@fstroj.uniza.sk

This Publication has to be referred as: Micieta, B[ranislav]; Jancusova, M[aria]; Macek, P[eter] \& Durica, J[an] (2014). Designing Measuring Equipment and Camera Systems in Manufacturing, Chapter 41 in DAAAM International Scientific Book 2014, pp.509-524, B. Katalinic (Ed.), Published by DAAAM International, ISBN 978-3-901509-98-8, ISSN 1726-9687, Vienna, Austria DOI:10.2507/daaam.scibook.2014.41 
Micieta, B.; Jancusova, M.; Macek, P. \& Durica, J.: Designing Measuring Equipme...

\section{Introduction}

Designing of prototype measuring equipment based unattended technologies require new approach to design and its application in manufacturing. Increase productivity, quality and energy are only possible with well designed and structured by automated equipment. The proposed research is focused on analysis and optimization of tools for new information and communication technologies (IKT) use. Mechanical design integration should be developed, aiming at approach for adapted to the measuring equipment in practical conditions of wood industry and other industry.

The paper introduces the newly developed concept used as a tool for comparing and qualitatively assessing impact of information and communication technologies use.

\section{Design of measuring equipment}

Design of measuring equipment with the designation AMZ-02 should be designed with a requirement for high stiffness of equipment because the momentum of the whole system must not affect the resulting data. In accordance with the requirements of practice, it was necessary to design the mechanical design of prototype automated measuring equipment which would be able to manipulate a person without access to such measured parts as well as with identification module. Methodology design optimization measuring equipment is used not only in the design of new facilities but also in optimizing so-called improvement of existing facilities. Correctly decision of designer to design a prototype measuring equipment in order to optimize the design requires high know-how (Jancusova \& Kubala, 2014). Measuring equipment is designed to automatically check the quality of parts with a choice of output parameters of the protocol. The operator has the option to add new parts to the system through visualization systems - Human Machine Interface (HMI). On learning of the system is necessary to define details which we will check, such as dimensions and field of tolerance for individual parts, and so on. Measuring equipment can be assembled in several versions.

Maximum dimensions of the measured part are 2000x1000x200mm.

The equipment is preferably designed to measure and control parts of the five sides. For comparison of technologies are designed two types of positioning subsystems. The first of positioning subsystem is a two-axis portal manipulator (Fig.1.) composed of linear motors and second of positioning subsystem is a combination of an industrial robot with additional axis (Fig.2.) to enlarge of the manipulating area.

The available we have proposed the following solutions and design two types of positioning subsystems:

- Portal manipulator;

- Robot with additional axis. 


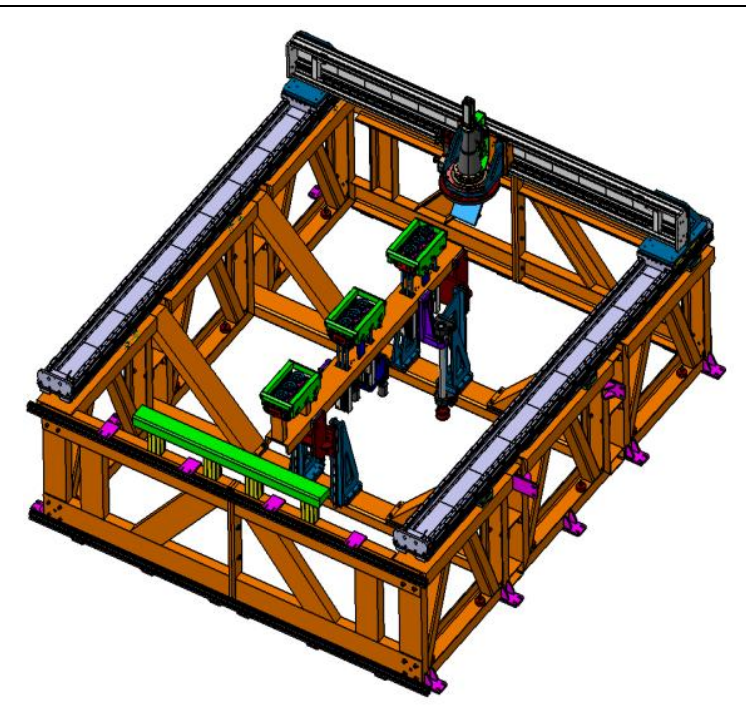

Fig. 1. First type of design of positioning subsystem in measuring equipment AMZ02: Portal manipulator (University of Zilina)

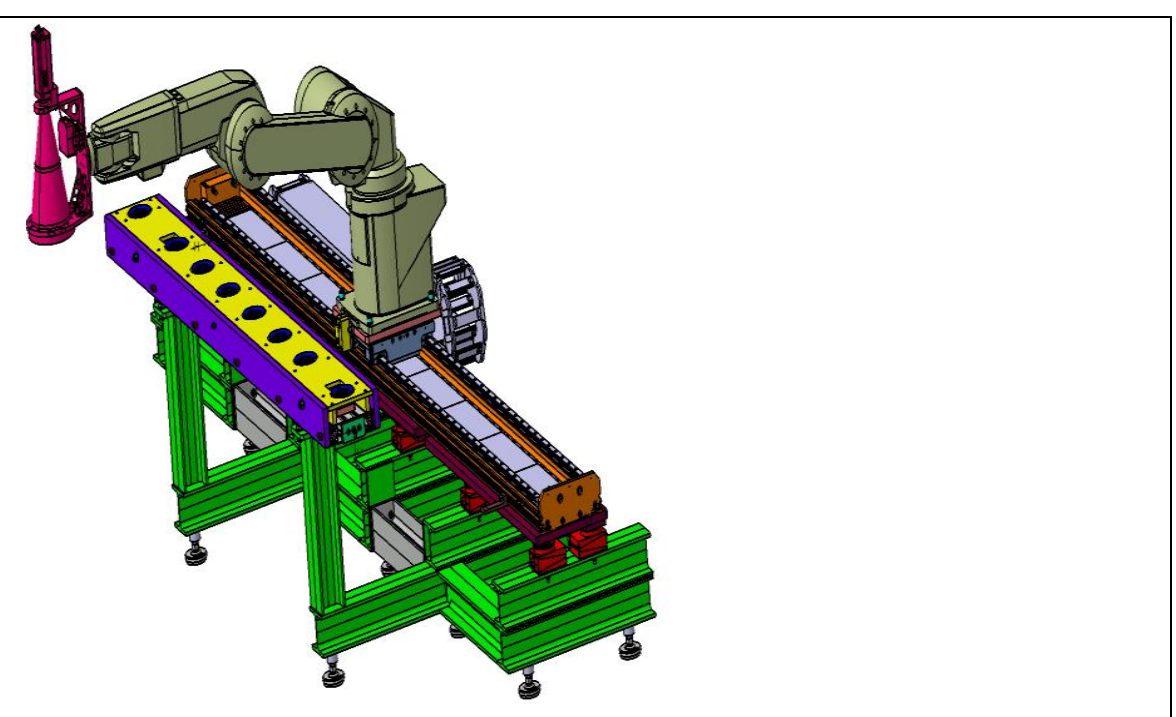

Fig. 2. Second type of design of positioning subsystem in measuring equipment AMZ-02: Robot with additional axis (University of Zilina)

\section{Basic factors in assembly system}

Assemblies are the product of the assembly process. This process involves defining the functions that the item must perform and then defining physical objects that will work together to deliver those functions. For these reasons, our approach to system design emphasizes careful specification of the information needed for good decisions. It also encourages the development of hybrid systems made up of suitable mixes of specialized or fixed automation, flexible automation, and people. Even though we present the topics in a particular sequence, it should be kept in mind that the actual process is highly iterative. Manufacturing system design can begin when a candidate product design is available along with the requirements for each process step and a candidate assembly sequence.

For these reasons, our approach to system design emphasizes careful 
Micieta, B.; Jancusova, M.; Macek, P. \& Durica, J.: Designing Measuring Equipme...

specification of the information needed for good design decisions. It also encourages the development of hybrid systems made up of suitable mixes of specialized or fixed automation, flexible automation, and people. Even though we present the topics in a particular sequence, it should be kept in mind that the actual process is highly iterative. A very simple model of the project is shown in Fig. 3.

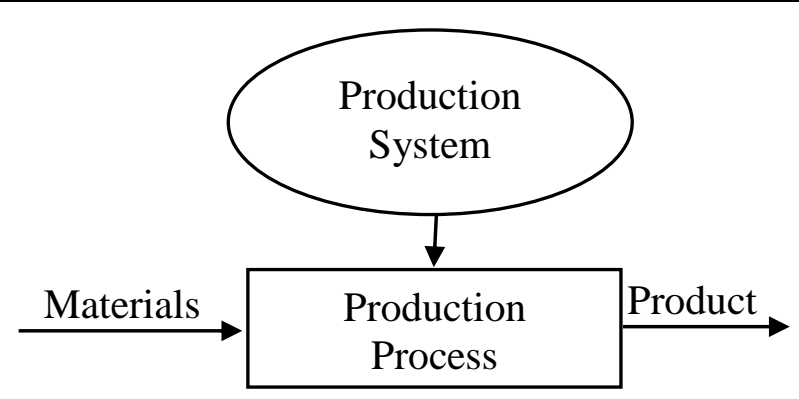

Fig. 3. Simple version of a project model

The system and the products both provide constraints to the design process. Some modifications to the product are design may be desirable or necessary.

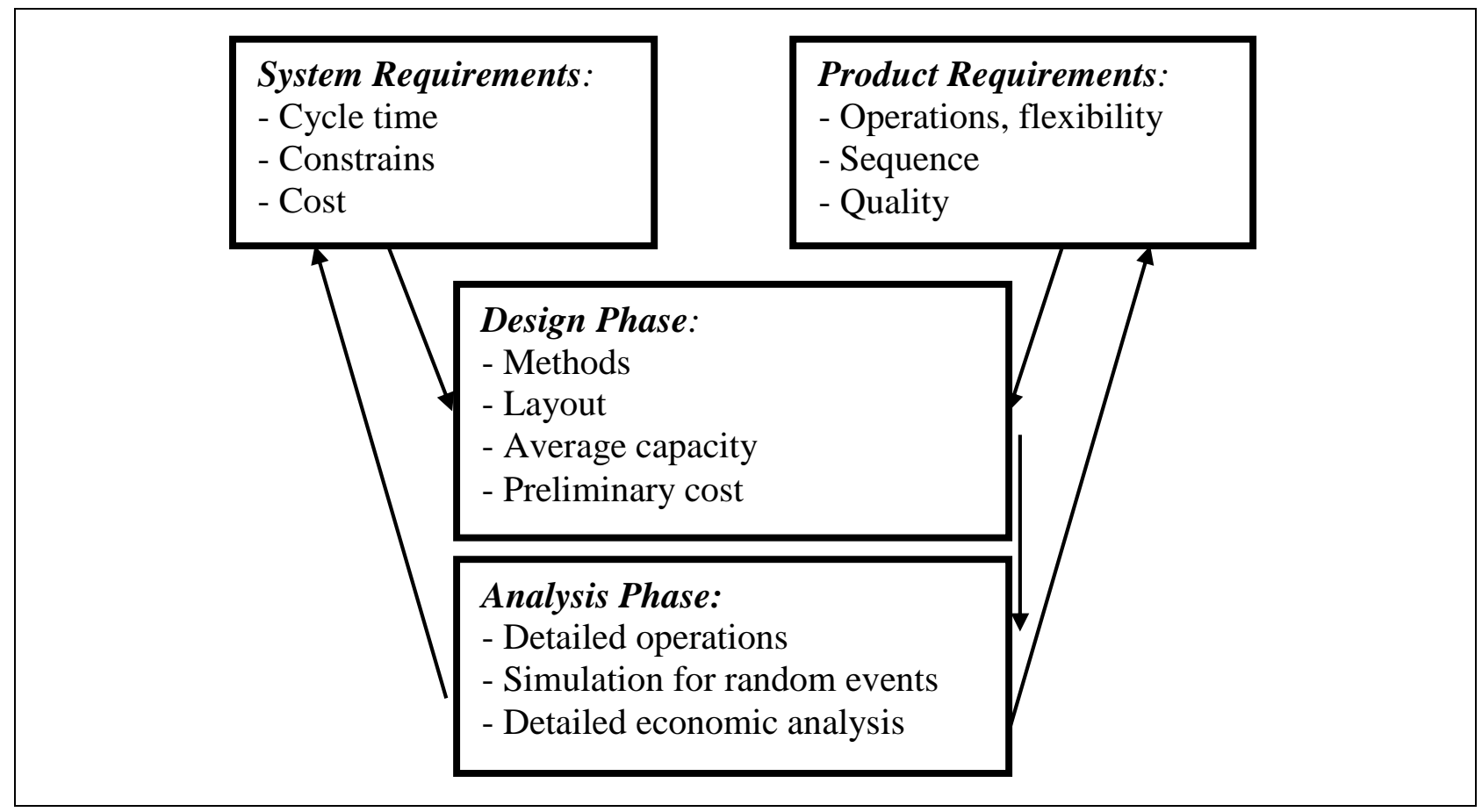

Fig. 4. Basic steps in designing an assembly system (Whitney, 2014)

The process is illustrated schematically in Figure 4. It comprises these steps:

1. Analyze the product and the necessary fabrication and assembly operations. Determine alternate fabrication methods, fabrication and assembly sequences, and candidate subassemblies. Determine fabrication and assembly process requirements. Assess the maturity of these processes and estimate process yield. Identify flexibility requirements such batch sizes and model mix. Identify problematic assembly steps and suggest product modifications. 
2. Select an assembly sequence for use in assembly system design.

3. Determine the production capacity required of the system, taking into account factors like downtime, time to switch models, employee breaks, process yield and other factors that effectively reduce capacity.

4. Tabulate feasible fabrication and assembly techniques (equipment or people) for each operation and estimate the time for each.

5. Using either intuitive techniques or the computerized method described later in this chapter, select a set of equipment or people that can make the product at the required rate for a reasonable cost.

6. Either makes preliminary economic analyses or proceeds to detailed workstation designs and then performs economic analyses.

\begin{tabular}{|c|c|c|}
\hline Domain & Context & Example Application \\
\hline Assembly in large & System level & $\begin{array}{l}\text {-Data management and control } \\
\text {-Quality management } \\
\text {-Subassemblies } \\
\text {-Assembly sequences } \\
\text {-Involvement of people } \\
\text {-Automation } \\
\text {-Line layout }\end{array}$ \\
\hline Assembly in small & Technical level & $\begin{array}{l}\text {-Individual party quality } \\
\text {-Individual part joining } \\
\text {-Part logistic, preparation and feeding } \\
\text {-Manual vs. Automatic } \\
\text {-Economic } \\
\text {-Ergonomic }\end{array}$ \\
\hline
\end{tabular}

Tab. 1. Assembly links unit manufacturing processes

At any stage in this process, economic or technical evidence may appear that forces a reconsideration of product design, selection of subassemblies or assembly sequences, timing requirements, and so on. If all of the required information is not available, or if system design reveals knowledge gaps, then additional product or process design effort, engineering, or experiments may be necessary. The alternative is a system design with less robustness and predictability than desirable. Product quality, delivery, or cost may suffer, or the time to reach full production may be prolonged, as a result.

In this table (Tab.1) the terms "assembly in the large" and "assembly in the small" are defined in context by means of the items at the far right in the table (Whitney, 2014). Manufacturing and assembly processes must be prepared. 
Micieta, B.; Jancusova, M.; Macek, P. \& Durica, J.: Designing Measuring Equipme...

\section{Design of methodology for automated assembly}

Design of equipment is completion process consists from a lot of information and conditions which have to be correct applied so as to get the optimal solutions. Input information for automated design assembly of equipment is:

- information about equipment (type, normalized units);

- information about product (profile, material, quality, economy);

- information about design and production equipment (design for manufacturing, systemic calculations, specification of machines.

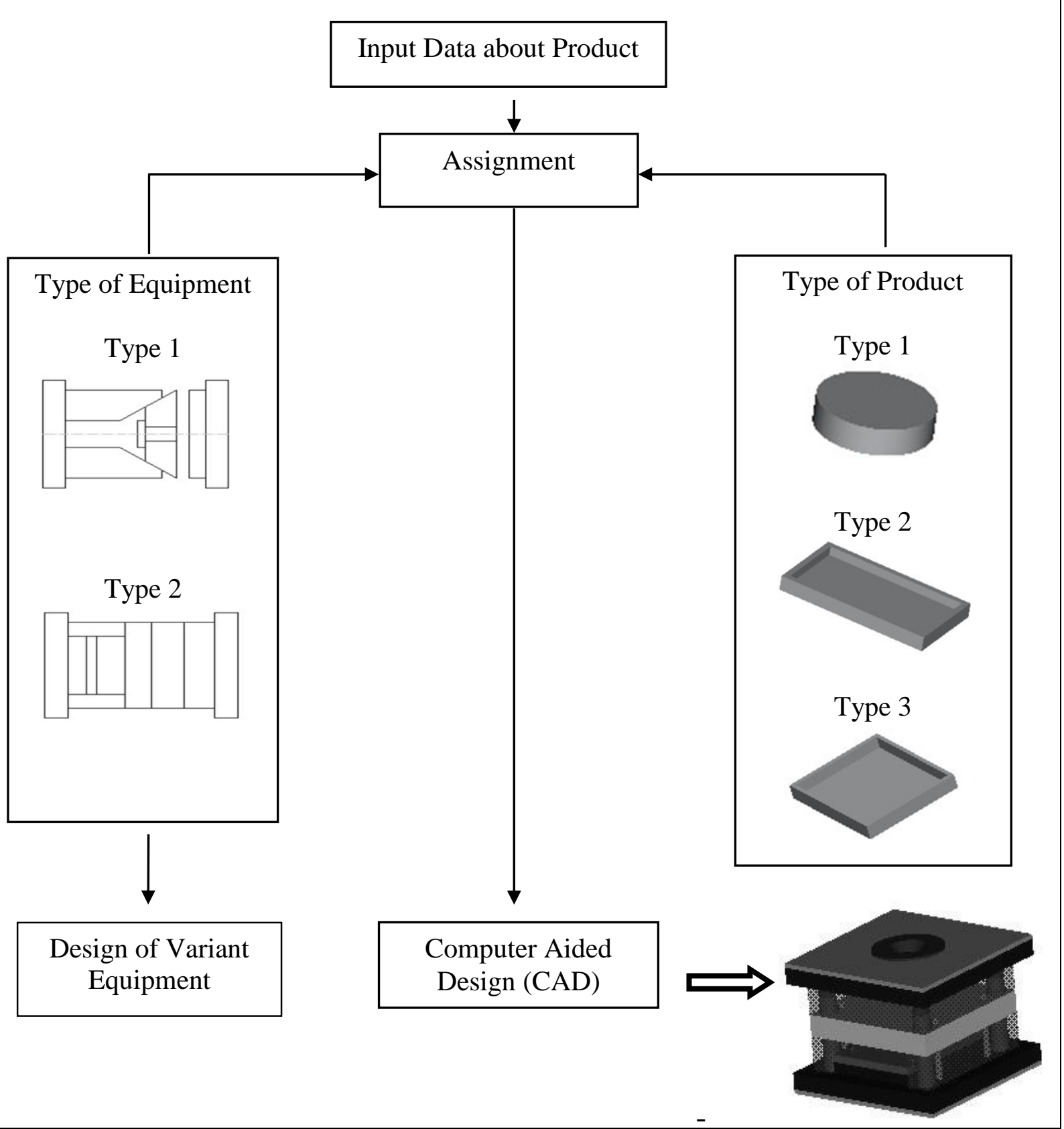

Fig. 5. Methodology for automated assembly 
The first database is database type of equipment. Variability of system in consist series production, standardized parameters of single boards and components, what make is possible assembling of equipment. The second database is database type of representation single products. Assignment products towards type representative of product are used of method principle of group technology which is used to the type similarity products. After assignment type of products toward type of equipment, we can input information system to generate assembly of equipment. This methodology for automation assembly is shown in Fig. 5.

Assembly is more than putting parts together. Assembly is the capstone process in manufacturing. It brings together all the upstream processes of design, engineering, manufacturing, and logistics to create an object that performs a function. The structure of the item must be defined, including all the interrelationships between the parts. Then each of the parts must be defined and given materials, dimensions, tolerances, surface finishes, and so on. The structure of the item must be defined, including all the interrelationships between the parts. It is important that the part design drawing be as clear as possible. Geometric tolerances are strongly recommended as a means of minimizing misinterpretation of dimensions (Micieta \& Stollmann, 2011). Instead, dimensioning should be related to product and assembly functions, such as clearances or interferences between mating dimensions of two parts of an assembly, etc. Specification of close tolerances where loose tolerances suffice will be costly to produce and to inspect.

\section{CAD/CAM Functions}

A user at a CAD graphics terminal can design a part, analyze stresses and deflections, study mechanical action, and produce engineering drawings automatically. And from geometric description provided by CAD, production people may produce $\mathrm{NC}$ instructions, generate process plans, program robots, and manage plant operations with a CAM system.

Experts group CAD functions in four major categories: geometric modeling, engineering analysis, kinematics, and automated drafting. And present activity in CAM technology centers around four main areas: numerical control, process planning, robotics, and factory management.

\section{Geometric Modeling}

The designer constructs a geometric model on the CAD/CAM terminal screen to describe the shape of a structure to the computer. The computer then converts thin pictorial representation into a mathematical model which it stores in a data base for later use. The model may be recalled and refined by the engineer at any point in the design process. And it may be used as an input for virtually all other CAD/CAM functions. Because so many functions depend on the model, geometric modeling is considered by many experts to be the most important feature CAD/CAM. Most modeling is done with wire frames that represent the part shape with interconnected line segments. Depending on the capabilities of the system, the model may be 2D, $2 \frac{1}{2} \mathrm{D}$, or a full $3 \mathrm{D}$ model. The technologies of $3 \mathrm{D}$ solid modeling and sculptured surfaces processing are two of the most recent advancements in geometric modeling. 
Micieta, B.; Jancusova, M.; Macek, P. \& Durica, J.: Designing Measuring Equipme...

And these areas continue to be refined and integrated with NC features. Eventually experts predict that integrated systems will be able to model and machine any general shape.

Engineering Analysis

Most CAD/CAM systems permit the user to move directly from the geometric model to analytical functions. For example, simple keyboard instructions may command the computer to calculate weight, volume, surface area, moment of inertia, or center of gravity of a part. In integrated systems, the user can call up the geometric model of the part and create a finite-element model quickly and easily using automatic node-generation and element-generation routines. Once a part is modeled, the user specifies loads and other parameters. Then the model may by analyzed with programs as ANSYS, SAP or NASTRAN. One of the most recent developments in $\mathrm{CAD} / \mathrm{CAM}$ analysis concerns the combination of analytical and experimental data to create a total system model. And characteristics of elastic components such as shock absorbers and isolation mounts are determined by testing. The data is combined to create a system model, which is then exercised to predict structural behavior during operation.

\section{Kinematics}

The equations associated with complex mechanisms such as four-bar linkages are extremely difficult to set up and solve. As a result, designers traditionally used pin-and-cardboard models or cumbersome graphical methods to develop practical mechanisms. CAD/CAM kinematics program now strip away of this tedium, cost, and complexity from mechanism design. Most systems can plot or even animate the motion of simple hinged parts such as doors and cranks to ensure they do not impact or interfere with other components. In addition, more sophisticated programs are available for designing and analyzing the most complex mechanisms. Hundreds of kinematics programs have been development in universities to solve very specialized problems, but only a few are refined sufficiently to be commercially practical.

Automated Drafting

Computer-assisted drafting features automatically produce detailed engineering drawings on command from the geometric-model data base or from inputs entered by the user at the graphics terminal. These systems have many features that automate a range of drafting tasks to speed the production of drawings. Most systems have automatic scaling and dimensioning features. And changes made to one view may be automatically added to other multiple views. Moreover, function menus permit the user to specify points, locate lines, enter text, and produce cross-hatching at the push of a button.

\section{Numerical control}

One of the most mature areas of CAD/CAM technology is numerical control, or NC. This is the technique of controlling a machine tool with prerecorded, coded information to make a part. NC instructions generally are stored on punched paper tapes or magnetic tapes for controlling the machine tool. More advanced systems may use computer numerical control (CNC), a set-up in which the machine is hardwired to minicomputer where NC instructions are stored. The most sophisticated systems use a direct numerical control (DNC) scheme in which several minicomputers are linked 
to a central mainframe. Some DNC systems eliminate the intervening minicomputer in favor of a direct interface between the central computer and machine tool. Traditionally, experienced programmers write NC instructions directly from engineering drawings. Then the program is tested on the machine tool and refined several times to remove errors. These time-consuming iterations can significantly increase the cost of machining a part.

Process planning

One important aspect of process planning systems is group technology. This concept organizes similar parts into families to allow fabrication steps to be standardized. Most process planning systems now use retrieval techniques. In this approach, process plans are developed for part families from existing data base on standard tooling and fabrication processes. One of the first of these systems was the CAM-I Automated Process Planning (CAPP) system. A commercial system called MIPLAN is also available from Organization for Industrial Research Inc. Retrieval systems are far from future generative process planning systems many experts predict. Generative process planning system currently under development by CAM-I would produce process plans directly from the geometric model data base almost no human assistance. The process planner would review the input from design engineering on a CAD/CAM terminal and then enter this data into the computer system which would automatically generate complete plans.

\section{Robotics}

Robots are automated manipulators arms that perform a variety of materialhandling tasks in the CAD/CAM systems. Robots may select and position tools and work pieces for NC machine tools. Or they may carry equipment or parts between various locations on the shop floor. They also may use their mechanical hands (called end effectors) to grasp and operate drills, welders, and other tools. Most robots presently are programmed in a so-called teach mode. In this approach a user physically leads the robot through the individual steps of an operation. This type of manual teach-programming is time-consuming and error-prone. Also, program changes usually require the entire sequence of steps to be repeated. Present for $\mathrm{CAD} / \mathrm{CAM}$ development have coordinated teams of robots and $\mathrm{NC}$ machine tools divided into group -technology work cells.

\section{Factory management}

Factory management ties together the other CAM areas to coordinate operations of the entire manufacturing facility. Factory management systems rely heavily on group technology, with individual manufacturing cells fabricating families of similar parts. And computers perform various management tasks such as inventory control and scheduling in material requirements planning (MRP) systems. Predictions are that individual manufacturing cells ultimately will be linked together and controlled by unified computer systems, paving the way for overall factory automation.

CAD/CAM system consisting of four information services Product, Process, Processor, and Production. These services support manufacturing activities through information storage, retrieval, communications, analysis, and processing. Associated with each services are specific CAM-I projects: Geometric Modeling (GM), 
Micieta, B.; Jancusova, M.; Macek, P. \& Durica, J.: Designing Measuring Equipme...

Sculptured Surfaces (SS), Process Planning (PP), Advanced Numerical Control (ANC), and Factory Management (FM).

The whole cycle depends largely upon the design process which, regardless of its structure, must be guided by a strong knowledge of design engineering, material and manufacturing (Gregor et al., 2006).

\section{Comparison and Specification of Measuring Subsystem}

Measuring equipment is configurable with respect to the desired final accuracy of measurement and type of the measured parts. We use to measuring equipment three variants of the measuring subsystem for the specifications of the measured part (Fig.6.).

The available we have these following solution and three variants of the measuring subsystems:

- 2D camera system with laser distance sensor;

- 3D camera;

- Configurable 3D camera system with option of the line scanning.

a)

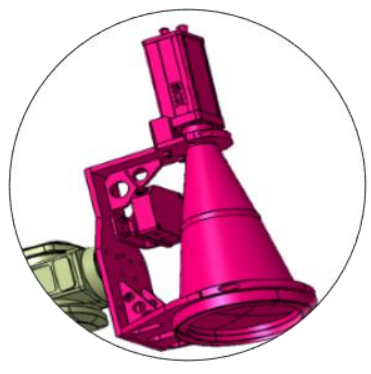

b)

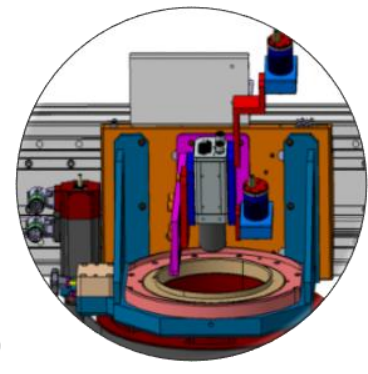

c)

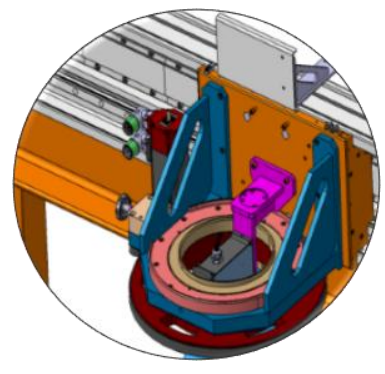

Fig. 6. Three camera systems used in measuring equipment AMZ-02: 2D camera with laser distance sensor (a), 3D camera (b), Configurable 3D camera with option of the line scanning $(\mathrm{c})$

From available the positioning and measuring subsystems are possible to assemble the control/measuring equipment, which are suitable for specific types of parts.

Subsystem with a 2D camera module with laser sensor is shown in Fig.7. The subsystem has a resolution of 1024 pixel x 768 pixel, telecentric lens with a field of view of $48 \mathrm{~mm} \times 36 \mathrm{~mm}$ and with a circular light and laser scanner. In this configuration, it is possible to achieve accuracy of $0,05 \mathrm{~mm}$ in the $\mathrm{X}$-axis, $\mathrm{Y}$-axis and 0,02mm in the Z-axis (Durica \& Macek, 2011).

The 2D camera module is suitable for controlling and measuring parts, their dimensions and details. The module is not suitable for complete control from point of view time consuming of scan the component. 


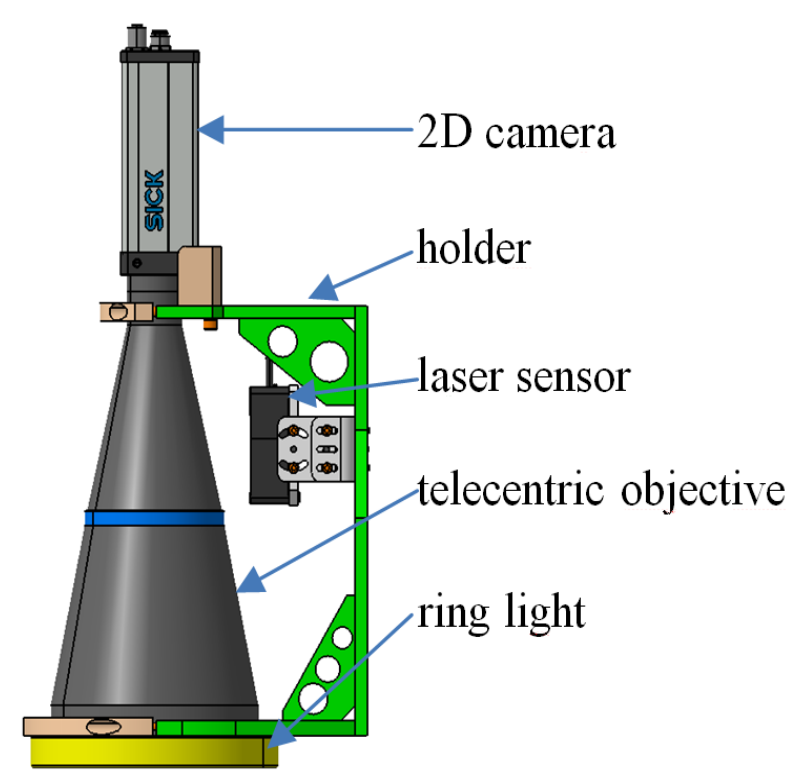

Fig. 7. Module of 2D camera system with laser sensor

The camera is equipped with a telecentric lens, which guarantees the preservation of the required accuracy in compliance with the camera distance measured from the panel to a certain range. Basic characteristics of camera system are shown in table 2 . and 3.

\begin{tabular}{|l|l|}
\hline Type of camera: & SICK IVC-2D HighRes Reader \\
\hline Technologies: & 2D, OCR/OCV, barcode reading \\
\hline Range: & $1024 \times 768$ \\
\hline Computing power: & $800 \mathrm{MHz}$ processor with FPGA \\
\hline Memory: & $128 \mathrm{MB}$ RAM, 16MB Flash \\
\hline Interface: & $10 / 100 \mathrm{Mbps}$ Ethernet, RS-485 \\
\hline Input /output: & $4 / 3$ \\
\hline Supply voltage: & $24 \mathrm{~V}$ \\
\hline
\end{tabular}

Tab. 2. Parameters of the camera system $(* *, 2014)$

\begin{tabular}{|l|l|}
\hline Type of sensor: & BALLUFF BOD 26K \\
\hline Sensing distance: & $45-85 \mathrm{~mm}$ \\
\hline Recovery time: & $2 \mathrm{~ms}$ \\
\hline Max. range: & $80 \mu \mathrm{m}$ \\
\hline Degree of protection: & IP 67 \\
\hline Working temperature: & -20 till +60 \\
\hline
\end{tabular}

Tab. 3. Parameters of the laser sensors $(* * *, 2014 \mathrm{c})$

If it is necessary to measure the position/dimension of detail in the Z-axis, handling subsystem moves laser scanner to a specific position on the basis of information provided by the camera system (Fig.8.). Because it is necessary to 
Micieta, B.; Jancusova, M.; Macek, P. \& Durica, J.: Designing Measuring Equipme...

measure components of the five sides and 2D camera module is approximately $400 \mathrm{~mm}$ high and prescribed distance of the telecentric lens from part is approximately $300 \mathrm{~mm}$, it was necessary to propose such a construction of portal manipulator that would not give too much error in the measurement. Because the serial rotary construction would require the addition of approximately $400 \mathrm{~mm}$ and errors in the positioning each rotary of axes should be transferred to the long arm is approximately $700 \mathrm{~mm}$, therefore was chosen as the static design of the camera and additional mirror (mirror surface area).

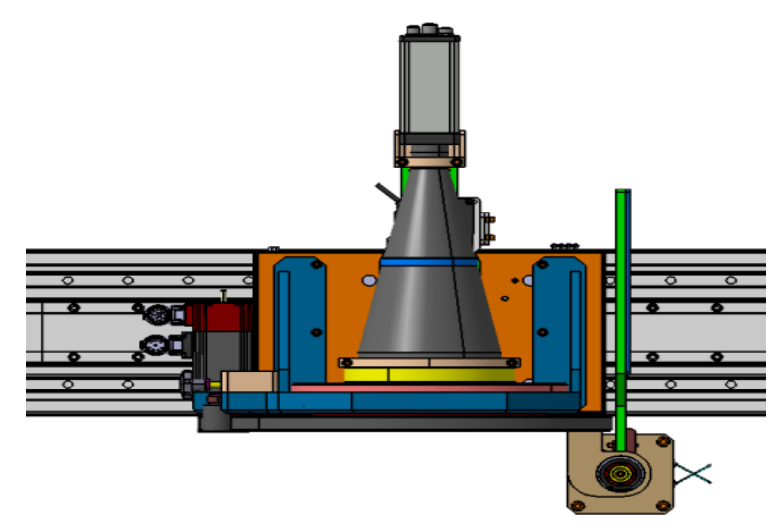

Fig. 8. Checking and measuring of component from TOP in measuring equipment AMZ-02

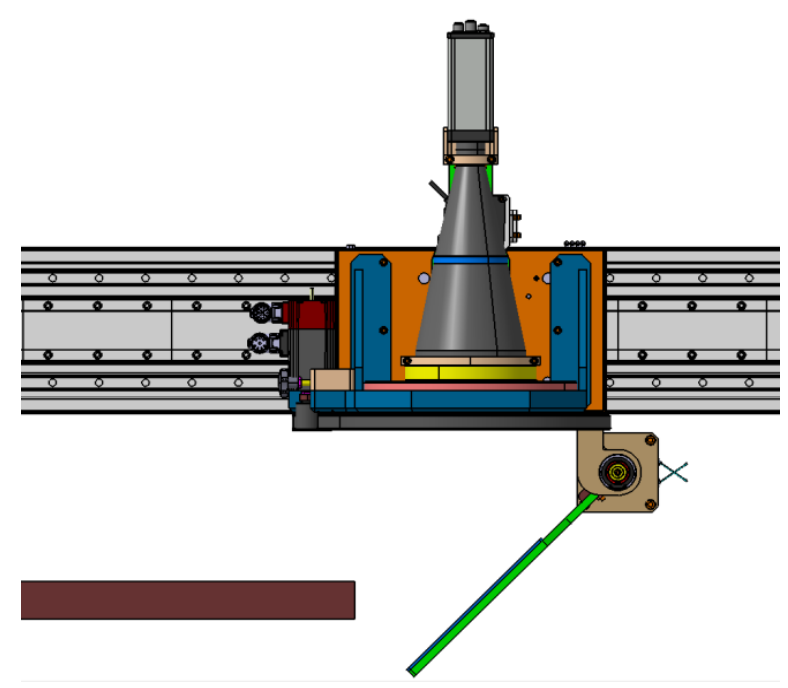

Fig. 9. Checking and measuring of component from SIDES in the measuring equipment AMZ-02 
If it is necessary, the mirror is inclined into the working position under an angle of 45 of degree and can rotate about a vertical axis (Fig.9.).

Subsystem with a 3D camera module has accuracy in the $\mathrm{X}$-axis and $\mathrm{Y}$-axis is $0,1 \mathrm{~mm}$ and in the $\mathrm{Z}$-axis is $0,03 \mathrm{~mm}$. Scheme of principle 3D camera system is shown in Fig.10. (***, 2014a). The maximum height of the measured component is $100 \mathrm{~mm}$, the width of the one scan is maximum $50 \mathrm{~mm}$. The $3 \mathrm{D}$ camera system consists of a line laser and camera system which are located in one housing with fixed geometry. As a whole is then calibrated by the manufacturer. The handling subsystem in the measuring process moves sensing subsystem with continuous movement in direction the $\mathrm{X}$-axis, then moves about $50 \mathrm{~mm}$ in direction the $\mathrm{Y}$-axis, and process is repeated until is scanned the whole part.

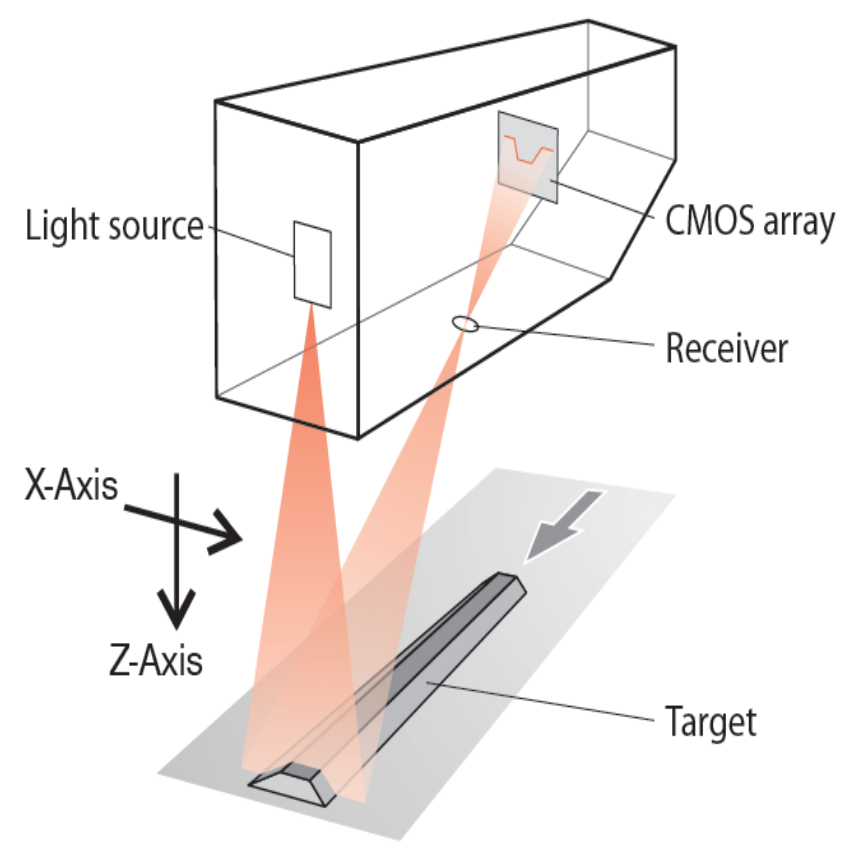

Fig. 10. Scheme of principle 3D camera system

Subsystem with a configurable 3D camera module, its scheme of principle 3D camera system is shown in Fig.11. (***, 2014a). The advantage of this subsystem is its openness. We can line laser of the geometry and 3D camera system to set to a specific range of products, thus we can reduce the unused parts of the visual field of the camera system, and thus we can increase the accuracy of the whole measuring subsystem. Subsystem must be calibrated after each change settings. The module has accuracy in the $\mathrm{X}$-axis and $\mathrm{Y}$-axis is $0,05 \mathrm{~mm}$ and in the $\mathrm{Z}$-axis is $0,03 \mathrm{~mm}$. This subsystem offers the possibility also $2 \mathrm{D}$ line scanning with an accuracy of $0,025 \mathrm{~mm}$ in the $\mathrm{X}$-axis. 


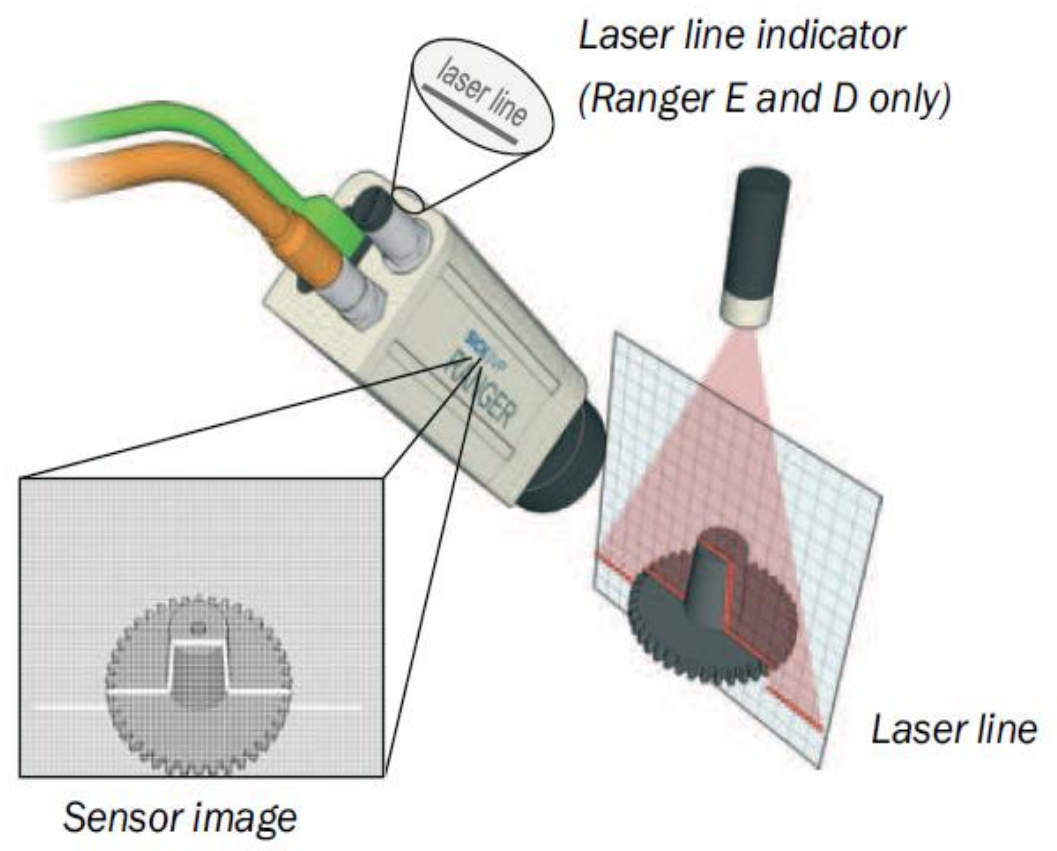

Fig. 11. Scheme of principle 3D camera system

The handling subsystem in the measuring process moves sensing subsystem with continuous movement in direction the X-axis, then moves about $100 \mathrm{~mm}$ in direction the $\mathrm{Y}$-axis and process is repeated until is scanned the whole part. The resulting display is possible to process and to save as a whole. In addition to the information provided 3D camera system also 2D data with 8-bit color depth. The camera systems are integral part for designing of the automated measuring equipment.

Program for the camera system can be created in IVC Studio development environment (Fig.12.). IVC Studio used in the creation of the program a number of tools for processing and image analysis. Creating a debugging program it is possible directly via an Ethernet connection using TCP protocol between the camera and the PC. In this case, the programming is any change in the program sent by the camera. It is also possible programming using emulation camera used. Defining action sequence using the available tools and setting their input parameters, you can create the desired program.

The camera system is used for measuring the position of individual entities wooden parts. To determine the depth of either entity is used a pair of laser sensors. The industrial computer PC is connected via analog module remote Input / Output. Both laser sensors are the same. Depending on the position of the measuring entity is one of the sensors intended to measure the surface of the reference member and the other for measuring the depth of the entity. 


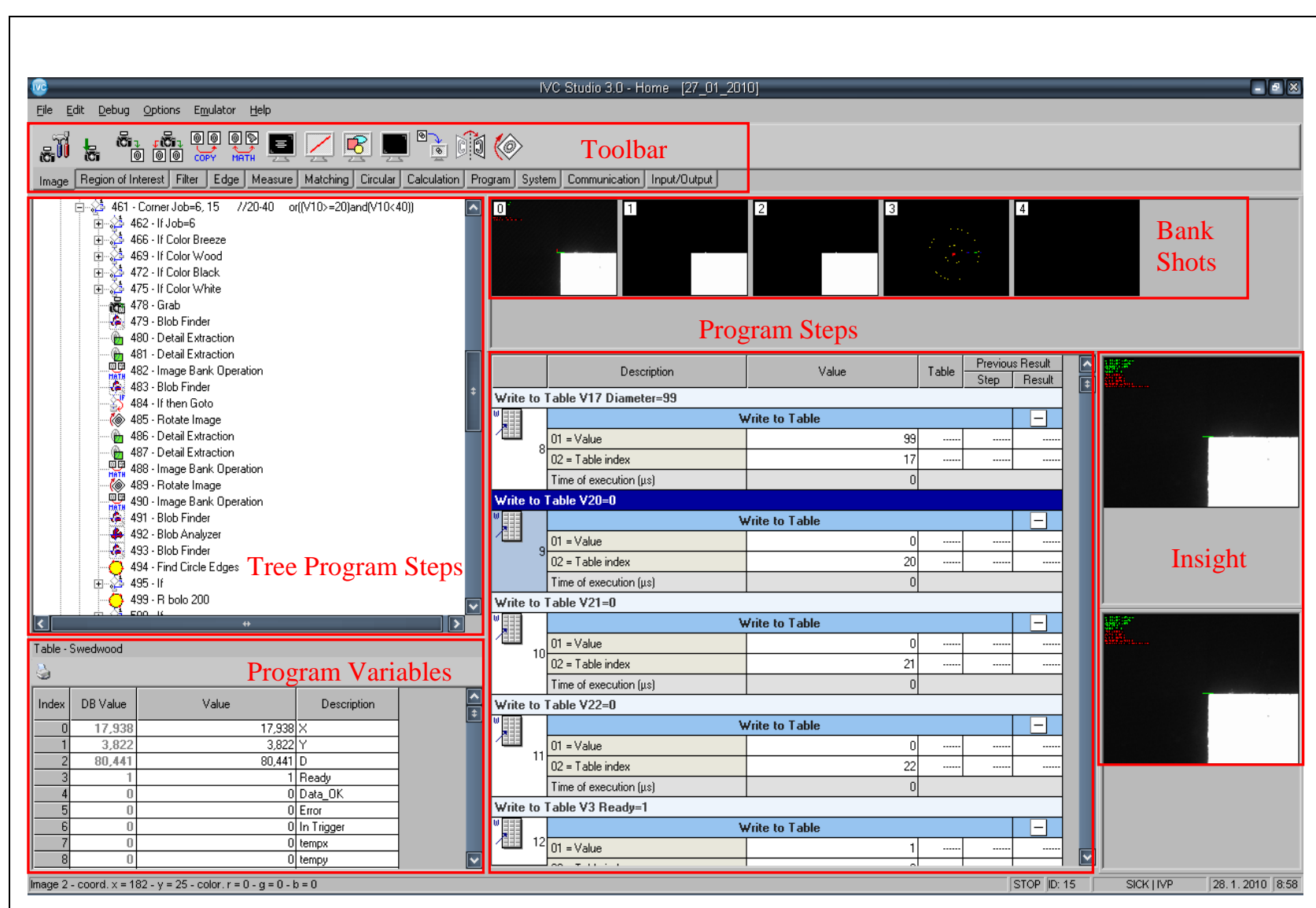

Fig. 12. IVC Studio-development environment (***, 2014b)

On both positioning mechanisms with interface for connecting all three measuring technologies are made the complete assembly. Air conditioning equipment is installed from the factory for change of the internal temperature conditions. For entering input conditions, control and monitoring of the whole control process we create by SCADA/HMI application (Hrubanik \& Rofar, 2013). Using of this application is possible for the operator to interactively intervene in the control process and on-line to compare the obtained results. Camera systems are integral components in designing measuring equipment. The machining process is highly automated and therefore different types of camera systems largely contribute to the analysis and identify the required parameters of the components in the process checking/measurement. Clamping and handling panels use a system of electromechanical and pneumatic elements. Modularity of whole mechanical and system platform of the equipment is equipped with system of connectors and quick clamping couplings.

\section{Conclusion}

Prototype of measuring equipment which is proposed based unattended technologies with possibility of using IKT for the needs of industrial practice. The advantage of the proposed equipment is an acceleration of itself process controls 
Micieta, B.; Jancusova, M.; Macek, P. \& Durica, J.: Designing Measuring Equipme...

manufactured parts, eliminate monotonous of manual check, further complete archiving of the achieved data, creation of the sophisticated system of calibration.

Recent design of measuring equipment can be regarded as one of the ways to develop so-called universal measuring equipment for measuring of complex parts which are based to new information and communication technologies.

Such proposed design of automated measuring equipment created the new universal platform will be used for unattended checking of dimensions of products in the wood industry and other industry.

\section{Acknowledgments}

This article was created thanks to funding and project implementation: ITMS code 26220220122 on the basis support of operational program: Research and Development Financed by the European Regional Development Fund.

\section{References}

Durica, J. \& Macek, P. (2014). Industrial Engineering Navigating the Future, Optical Measure Systems in AMZ02, pp.54-57, ISBN 978-80-554-0879-8, Korna, 06, 2014, University of Zilina, EDIS-University Publisher, Zilina, Slovakia

Gregor, M.; Medvecky, S.; Micieta, B.; Matuszek, J. \& Hrcekova, A. (2006). Digital Factory, EDIS-University Publisher, ISBN 80-969391-5-7, Zilina, Slovakia

Hrubanik, P. \& Rofar, J. (2013). Transcom 2013, OPC in SCADA/HMI application for modular quality control system, pp.131-134, ISBN 978-80-554-0695-4, Zilina, 06, 2013, University of Zilina, EDIS-University Publisher, Zilina, Slovakia Jancusova, M. \& Kubala, M. (2013). Designing of Automated Measuring Equipment with aspect to optimation, Technolog, No. 05/2013, pp. 23-27, ISSN 1337-8996 Micieta, B. \& Stollmann, V. (2011). Assembly Line Balancing, Chapter 21 in DAAAM International Scientific Book 2011, pp. 257-264, Editor B. Katalinic, Publisher by DAAAM International, ISBN 978-3-901509-84-1, ISSN 1726-9687, Vienna, Austria

Whitney, Daniel E. (2004). Mechanical Assemblies, Oxford University Press, ISBN 0-19-515782-6, New York, USA

*** (2014a) http://www.sick.com

*** (2014b) http://www.sickivp. se/ch/products/highlights/ automatisierungstechnik/ ivc/ivc2d/de.toolboxpar.0010.file.tmp/IVC-2D\%20Product\%20Information.pdf *** (2014c) http://www.balluff.com/ Balluff/ Documents/datasheets/ BOD26K _LA01_S4_C_en.pdf 